\title{
Leucocytosis Predicts Survival in Metastatic Non Small Cell Lung Carcinoma Patients-A Retrospective Review of a Single Institution Data
}

\author{
Lamiae Amaadour ${ }^{1 *}$, Zineb Benbrahim ${ }^{1}$, Nadia Benaicha ${ }^{2}$, Fatima Zahra Elmrabet ${ }^{1}$, \\ Samia Arifi ${ }^{1}$, Chakib Nejjari², Nawfel Mellas ${ }^{1}$ \\ ${ }^{1}$ Departement of Medical Oncology, Hassan II University Hospital, Fez, Morocco \\ ${ }^{2}$ Laboratory of Epidemiology and Biostatistics, Faculty of Medicine of Fez, Fez, Morocco \\ Email: *lamiae.amaadour@gmail.com
}

How to cite this paper: Amaadour, L., Benbrahim, Z., Benaicha, N., Elmrabet, F.Z., Arifi, S., Nejjari, C. and Mellas, N. (2017) Leucocytosis Predicts Survival in Metastatic Non Small Cell Lung Carcinoma Patients-A Retrospective Review of a Single Institution Data. Journal of Cancer Therapy, 8, 948-953.

https://doi.org/10.4236/jct.2017.811084

Received: October 18, 2017

Accepted: November 18, 2017

Published: November 21, 2017

Copyright $\odot 2017$ by authors and Scientific Research Publishing Inc. This work is licensed under the Creative Commons Attribution International License (CC BY 4.0).

http://creativecommons.org/licenses/by/4.0/

\section{(c) (i) Open Access}

\begin{abstract}
Background: Tumor-related leukocytosis is a paraneoplastic syndrome that is encountered occasionally in the clinical course of patients with lung carcinoma. The aim of this study is to evaluate the prognostic significance of leucocytosis in patients with metastatic non small cell lung carcinoma. Methods: We retrospectively reviewed 205 cases of metastatic non small cell lung carcinoma diagnosed between January 2007 and December 2012 at the department of medical oncology, Hassan II University Hospital of Fez, Morocco. Clinical and laboratory data were collected including white blood cells at baseline. Leucocytosis was studied in relation to overall survival and progression free survival. Results: The frequency of leucocytosis was of $57.5 \%$. Patients with leucocytosis had shorter overall survival (OS, $p=0.015)$ and disease-free survival (DFS, $\mathrm{p}<0.0001)$ than those without leucocytosis. In multivariable analysis, patients with leucocytosis had a significantly greater risk of death and recurrence than those without leucocytosis. Conclusion: Leucocytosis was valuable for predicting the prognosis of patients with metastatic non small cell lung carcinoma.
\end{abstract}

\section{Keywords}

Paraneoplastic Leucocytosis, NSCLC, Metastatic Stage, Survival

\section{Background}

Lung cancer is the leading cause of cancer related death worldwide [1]. Non- 
small cell lung cancer (NSCLC) accounts for approximately $80 \%$ of all lung cancers. There are several known prognostic factors for patients with NSCLC. An increased level of white blood cells (WBC) is frequently observed in the clinical course of patients with NCSLC. It may be caused by many factors such as infection, bone marrow metastasis, or administration of corticosteroids [2] [3]; without these conditions, patients with lung carcinoma can be considered to have paraneoplastic leucocytosis or tumor related leucocytosis (TRL) [4]. It remains unclear whether TRL is the final result of advanced malignancies or the direct cause that increases the risk of progression and death. Several previous studies suggested that TRL in patients with advanced stages of NSCLC might have a negative impact on survival [5] [6].

The aim of this study is to evaluate the prognostic value of TRL in patients with metastatic NSCLC.

\section{Methods}

\subsection{Patients}

We retrospectively reviewed 205 patients who were diagnosed with metastatic NSCLC at our institution during a period of 6 years (from January 2007 to December 2013). Data on patient demographics, laboratory results, pathology based on the seventh edition of the American Joint Committee on Cancer staging system, treatment and outcome were evaluated. Diagnosis of all patients was confirmed by histologic examination. Complete blood cell count was performed at the time of diagnosis and prior to treatment. Leucocytosis was defined as an absolute white blood cell count $>10.000 / \mathrm{mm}^{3}$ with no evidence of infection.

\subsection{Statistical Analysis}

Overall survival (OS) and disease-free survival (DFS) were defined as the time elapsed between the date of treatment and the date of death and the date of recurrence, respectively. Significant differences in variables in relation to leucocytosis were tested using chi-square test or Fisher's exact test, as appropriate. OS and DFS were evaluated using Kaplan-Meier analysis, and comparisons of survival between the two groups were made using the log-rank test. The relative impact of variables was analyzed by univariate analysis using the Cox proportional hazards regression method. Multivariate analysis was performed using a backward stepwise method. Variables with clinical significance and statistical significance levels of less than 0.05 were selected for covariate analysis. Variables with a $P$ value of more than 0.10 were removed during stepwise analysis. Two-tailed $P$ values of less than 0.05 were considered statistically significant. All statistical analyses were performed using the SPSS statistical software package.

\section{Results}

The study population was predominantly men (85.5\%). The median age was of $57.8 \pm 10$ years. Among 205 patients, there were 171 (83.4\%) current or past 
smokers. $117(57.5 \%)$ of patients had leucocytosis at the time of diagnosis with a mean of $15820 / \mathrm{mm}^{3}$. Histologically, $107(52.2 \%)$ of patients had adenocarcinoma, 53 (25.6\%) patients had squamous cell carcinoma, and 45 (22.2\%) patients had other histopatological features. Concerning performance status (PS), leucocytosis was more frequently associated with poor PS (2/4 on the ECOG scale) ( $23 \%$ vs $14.7 \%, p=0.0001)$. However, it was not correlated to age, gender, body mass index, number of metastatic sites, bone metastasis, liver metastasis, hypercalcemia, anemia and hypoalbuminemia. The treatment consisted of palliative doublet of platinum based chemotherapy in $72.6 \%$ of cases, monochemotherapy in $18 \%$ of cases and best supportive care in $9.4 \%$ of cases.

The median follow up period was of 10.4 months (Range: 1 - 42). On univariate analysis, the overall survival of patients with leucocytosis was significantly lower than that of patients without leucocytosis: median 5 vs 7.3 months, $\mathrm{p}=$ 0.015, (Figure 1).

Progression free survival of patients with leucocytosis was significantly lower than that of patients without leucocytosis: median 3.2 versus 6.5 months, $\mathrm{p}<$ 0.0001 (Figure 2).

On multivariate analysis, leucocytosis was independent negative prognostic factor for OS.

\section{Discussion}

Our findings demonstrated that leucocytosis at the time of diagnosis in patients with metastatic NSCLC was significantly associated with an increased risk of death and disease progression in both univariate and multivariate analysis. In addition, the negative prognostic impact of leucocytosis on survival is compa-

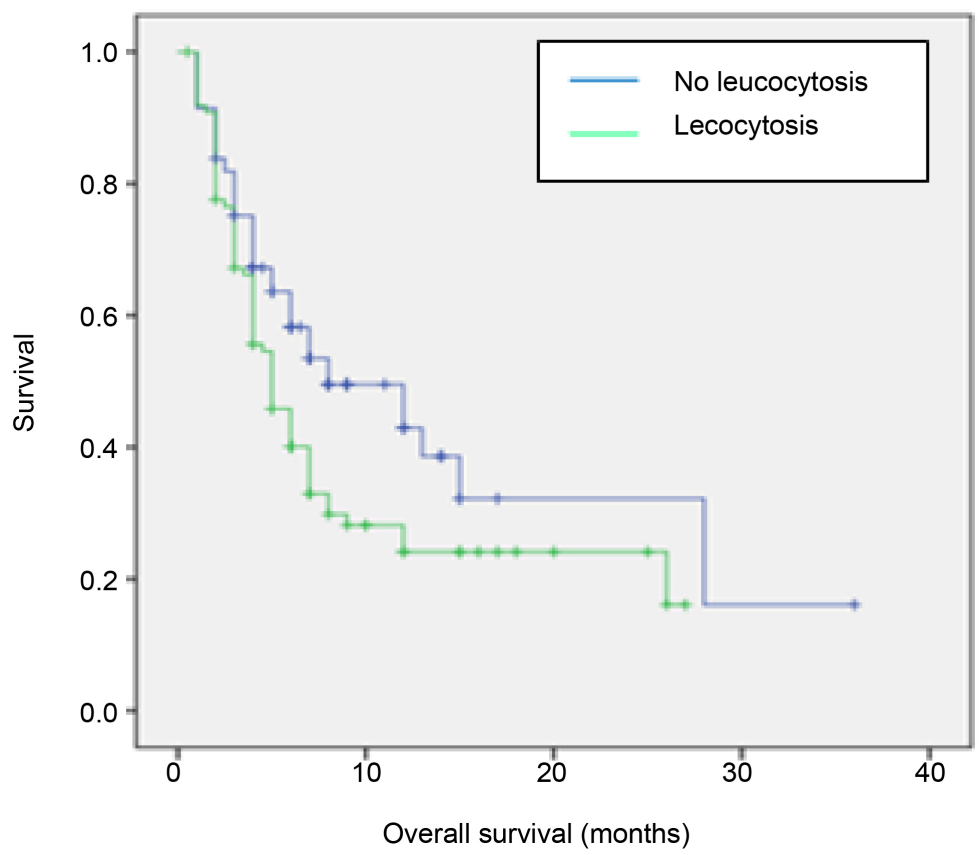

Figure 1. Correlation between leucocytosis and overall survival. 


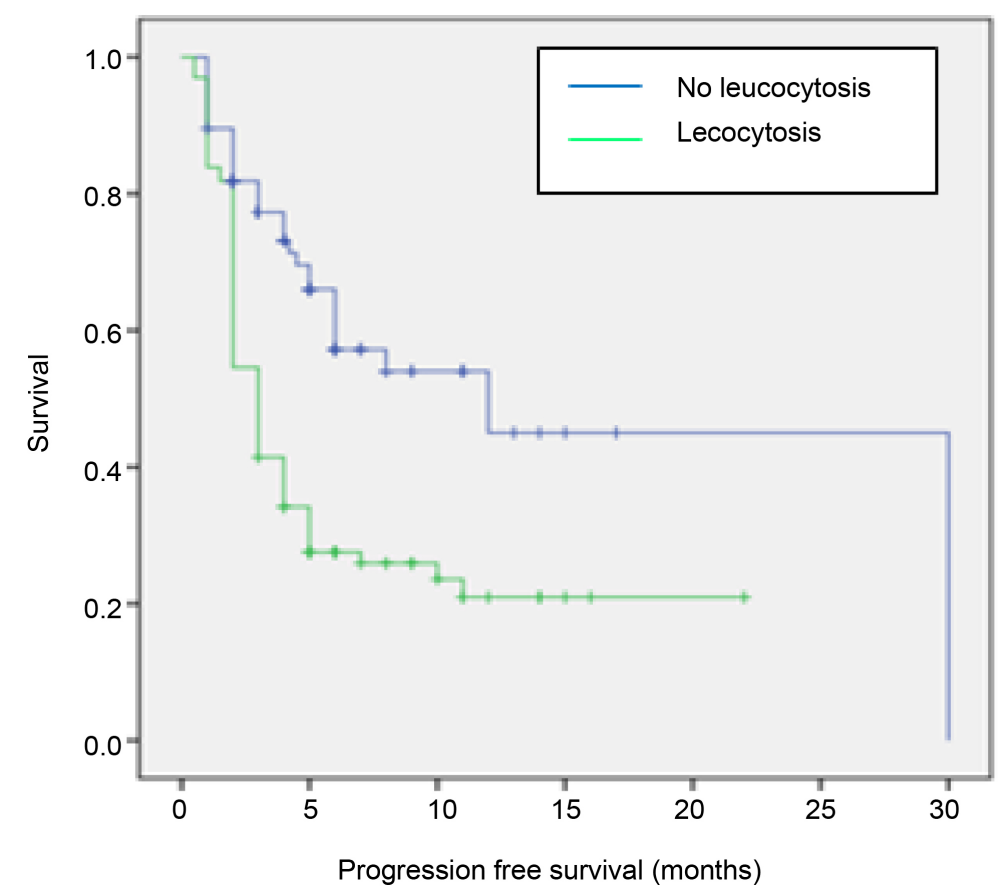

Figure 2. Correlation between leucocytosis and Progression free survival.

rable with having poor performance status. There have been many clinical and histological prognostic factors influencing survival identified in NSCLC patients and some of these, including tumor stage, histological subtype and performance status, are being used presently for treatment decision making [7]. Recently, research has been conducted concerning novelmolecularprognostic biomarkers such as epidermal growth factor receptor (EGFR); however these markers are often expensive and time-consuming to measure, especially in low incoming countries, and their prognostic value in NSCLC patients remains to be confirmed [8]. Therefore, identifying additional reliable prognostic markers that are inexpensive and easy to use are of importance to guide the treatment choice for each patient.

Leucocytosis in patients with malignant disease is usually caused by infection, bone marrow metastasis or the administration of corticodteroids. However, unexplained leucocytosis is found occasionally in patient with cancer; it thought to be caused by tumoral production of hematopoietic cytokinessuch as granulocyte-colony-stimulating factor [4] [6] [14]; this paraneoplastic phenomenon, known as tumor-related leukocytosis (TRL), occurs most frequently in patients with lung carcinoma, although it can occur in any type of malignant neoplasm [9] However, the precise incidence and characterization of TRL in patients with lung carcinoma remains obscure.

Several previous studies suggested that leucocytosis in patients with NSCLC might have a negative impact on survival [6] [10]. In a pooled analysis of North Central Cancer Treatment Group (NCCTG) trials, leucocytosis was associated with worse overall survival with a HR of 1.43 compared to patients with normal 
white blood count [11] [12] [13].

Although there is increasing evidence that leucocytosis contributes to tumor progression and metastasis, the molecular mechanisms through which leucocytes worsen prognosis of cancer patients still need to be studied.

The strengths of our study consist of its homogenous and well-defined patient population; Limitations include a retrospective review of data, and the limited patient population, so our results should be interpreted cautiously.

\section{Conclusion}

The results of the present study showed the significant association between leucocytosis and patient survival. Based on these findings, it is most likely that the association of the preoperative abnormal white blood cell counts with patient survival is mainly due to a more aggressive tumor behavior. Further studies are needed to confirm these results.

\section{Disclosure}

All the authors declare no conflict of interest.

\section{References}

[1] Siegel, R., Naishadham, D. and Jemal, A. (2013) Cancer Statistics, 2013. CA: $A$ Cancer Journal for Clinicians, 63, 11-30. https://doi.org/10.3322/caac.21166

[2] Slungaard, A., Ascensao, J., Zanjani, E. and Jacob, H.S. (1983) Pulmonary Carcinoma with Eosinophilia. The New England Journal of Medicine, 309, 778-781. https://doi.org/10.1056/NEJM198309293091307

[3] Ascensao, J.L., Oken, M.M., Ewing, S.L., Goldberg, R.J. and Kaplan, M.E. (1987) Leukocytosis and Large Cell Lung Cancer. A Frequent Association. Cancer, 60, 903-905. https://doi.org/10.1002/1097-0142(19870815)60:4<903::AID-CNCR2820600431>3.0 .CO;2-6

[4] Asano, S., Urabe, A., Okabe, T., Sato, N., Kondo, Y., Ueyama, Y., et al. (1977) Demonstration of Granulopoietic Factors in the Plasma of Nude Mice Transplanted with a Human Lung Cancer and in the Tumor Tissue. Blood, 49, 845-852.

[5] Deng, Q., Yang, H., Zhang, X., Chen, H., Qiu, Y., Wen, D., Xiong, X., Wang, W. and He, J. (2010) Correlation between Pre-Treatment Anemia and Prognosis in Non-Small Cell Lung Cancer Patients. Zhongguo Fei Ai Za Zhi, 13, 722-726.

[6] Maione, P., Rossi, A., Di Maio, M. and Gridelli, C. (2009) Tumor-Related Leucocytosis and Chemotherapy-Induced Neutropenia: Linked or Independent Prognostic Factors for Advanced Non-Small Cell Lung Cancer? Lung Cancer, 66, 8-14. https://doi.org/10.1016/j.lungcan.2009.02.022

[7] Brundage, M.D., Davies, D. and Mackillop, W.J. (2002) Prognostic Factors in NonSmall Cell Lung Cancer: A Decade of Progress. Chest, 122, 1037-1057. https://doi.org/10.1378/chest.122.3.1037

[8] Donnem, T., Bremnes, R.M., Busund, L.T., et al. (2012) Gene Expression Assays as Prognostic and Predictive Markers in Early Stage Non-Small Cell Lung Cancer. Journal of Thoracic Disease, 4, 212-213.

[9] Mckee Jr., L.C. (1985) Excess Leukocytosis (Leukemoid Reaction) Associated with 
Malignant Diseases. The Southern Medical Journal, 78, 1475-1482.

https://doi.org/10.1097/00007611-198512000-00018

[10] Kasuga, I., Makino, S., Kiyokawa, H., et al. (2001) Tumor-Related Leukocytosis Is Linked with Poor Prognosis in Patients with Lung Carcinoma. Cancer, 92, 23992405.

https://doi.org/10.1002/1097-0142(20011101)92:9<2399::AID-CNCR1588>3.0.CO;2-W

[11] Ferrigno, D. and Buccheri, G. (2003) Hematologic Counts and Clinical Correlates in 1201 Newly Diagnosed Lung Cancer Patients. Monaldi Archives for Chest Disease, 59, 193-198.

[12] Mandrekar, S.J., Schild, S.E., Hillman, S.L., et al. (2006) A Prognostic Model for Advanced Stage Nonsmall Cell Lung Cancer. Pooled Analysis of North Central Cancer Treatment Group Trials. Cancer, 107, 781-792.

https://doi.org/10.1002/cncr.22049

[13] Tibaldi, C., Vasile, E., Bernardini, I., et al. (2008) Baseline Elevated Leukocyte Count in Peripheral Blood Is Associated with Poor Survival in Patients with Advanced Non-Small Cell Lung Cancer: A Prognostic Model. Journal of Cancer Research and Clinical Oncology, 134, 1143-1149. https://doi.org/10.1007/s00432-008-0378-2

[14] Gislason, T. and Nou, E. (1985) Sedimentation Rate, Leucocytes, Platelet Count and Haemoglobin in Bronchial Carcinoma: An Epidemiological Study. European Journal of Respiratory Diseases, 66, 141-146. 